Pacific Journal of Mathematics

ON CLOSED MAPPINGS, BICOMPACT SPACES, AND A 


\section{ON CLOSED MAPPINGS, BICOMPACT SPACES, AND A PROBLEM OF P. ALEKSANDROV}

\section{A. Arhangel'skiI}

The purpose of this paper is to show, under very general circumstances, that if $f: X \rightarrow Y$ is a closed map, then $f^{-1} y$ must be bicompact for "most" $y \in Y$. Two theorems of this sort are obtained, one of which is then used to answer a question of $P$. Alexandroff on the effect of closed maps on countable-dimensional spaces.

If $f: X \rightarrow Y$ is a closed map, then it is known that, under suitable assumptions, $f^{-1} y$ has a bicompact boundary for all $y \in Y$ (see I. Vaǐnšteľn [19], A. H. Stone [18], and K. Morita and S. Hanai [12]), and $f^{-1} y$ itself is bicompact for "most" $y \in Y$ (see K. Morita [11] and the author [4]). In $\S \S 1$ and 2 of this paper, we prove two theorems of the latter kind, whose main feature is that they require minimal restrictions on $X$ and no restriction at all (other than being $T_{1}$ ) on $Y$.

In $\S 3$, we give some applications of the results from $\S 2$. The most interesting among them is the following, which gives a complete answer to a question of P. Alexandroff, (Terminology is defined below).

THEOREM (3.1). Let $X$ be a countable-dimensional space with a countable net, and let $f: X \rightarrow Y$ be a closed mapping of $X$ onto some uncountable-dimensional space $Y$. Then $Y_{1}=\left\{y \in Y \mid\right.$ card $\left.\left(f^{-1} y\right) \geqq \mathfrak{c}\right\}$ is uncountable-dimensional.

Observe that Theorem 3.1 is new even in case $X$ is compact metric. In that case, E. Skljarenko [15] has shown that $Y_{1}$ is not void, but his proof gives no further information about $Y_{1}$. Our proof is based on entirely different ideas.

Let me say here that I am very grateful to $P$. Alexandroff for valuable discussions about this question and to E. Michael for helping with the translation of this paper.

Notation and terminology. All spaces are completely regular (often is it sufficient to suppose $T_{1}$ ); all mappings are continuous, and all coverings are open. We call a family $\gamma=\{S\}$ of sets $S \subseteq X$ a net in $X$, if, for every $x \in X$ and each open $U$ containing $x$, there exists an $S \in \gamma$ with $x \in S \subseteq U$ (see [3]). We write card $A$ for the cardinality of $A$, and $c$ for the cardinality of the continuum. If $\gamma$ is a family of subsets of a space $X$, and if $x \in X$, then $\gamma x$ denotes the union of all elements of $\gamma$ containing $x$. As usual, we call a space countabledimensional if it is a countable union of subspaces with $\operatorname{dim}=0$; 
otherwise, we call the space uncountable-dimensional. We write $\beta X$ for the Stone-Čech bicompactification of $X$, and we call $X$ a $G_{\delta}$-space if it is a $G_{\delta}$ in $\beta X$. We call $X$ point-paracompact if every (open) covering of $X$ has an (open) point-finite refinement. Finally, $X$ is called a $k$-space if a subset $U \subseteq X$ is open whenever its intersection with every compact $K \subseteq X$ is open in $K$.

\section{Closed mappings of point-paracompact $\mathbf{G}_{\delta}$-spaces.}

THEOREM (1.1). Let $X$ be a point-paracompact $G_{\delta}$-space, and let $f: X \rightarrow Y$ be a closed map. Then

$$
Y=Y_{0} \cup\left(\bigcup_{n=1}^{\infty} Y_{n}\right),
$$

where $Y_{n}$ is discrete in $Y$ for all $n$, and $f^{-1} y$ is bicompact for all $y \in Y_{0}$.

For the proof of this theorem, we need

LEMMA (1.2). Let $X$ be a k-space, let $\gamma$ be a point-finite covering of $X$, and let $f: X \rightarrow Y$ be a closed mapping of $X$ onto some $Y$. Then

$$
N=\left\{y \in Y \mid \text { no finite } \gamma^{\prime} \subseteq \gamma \text { covers } f^{-3} y\right\}
$$

is discrete in $Y$.

Proof. Suppose that some $y \in Y$ is an accumulation point for $N$. Then the set $N_{1}=N \backslash y$ is not closed. Since $X$ is a $k$-space and $f$ a closed mapping, $Y$ is a $k$-space [8]. Therefore there exists a bicompact $F \subseteq Y$ such that $F \cap N_{1}$ is not closed, and hence is infinite. Let $\left\{y_{n}\right\}$ be a sequence of distinct points from $F \cap N_{1}$. Since $F$ is bicompact, there exists an accumulation point $y^{\prime}$ for this sequence, which we may suppose different from all $y_{n}$. We let $A_{n}=f^{-1} y_{n}$ for $n=1,2, \cdots$. Next we shall define a sequence $\left\{x_{n}\right\}$, with $x_{n} \in A_{n}$, where for $x_{1}$ we take any point from $A_{1}$. Suppose the points $x_{k}$ are defined for all $k<m$. We take for $x_{m}$ any point of the set $A_{m} \backslash \bigcap_{i=1}^{m-1} \gamma x_{i}$; this set is not empty by the very definition of $N$.

Now we prove that the sequence $\left\{x_{n}\right\}$ is discrete. Consider any point $x \in X$. We only have to consider the case where $\gamma x \cap\left\{x_{n}\right\} \neq \varnothing$. Let $x_{m} \in \gamma x$; then $x \in \gamma x_{m}$ and $U=\gamma x_{m}$ is a neighborhood of $x$; by the definition of $x_{n}$, this $U$ can contain only points $x_{n}$ with $n \leqq m$. Thus the discreteness of $\left\{x_{n}\right\}$ is proved.

It follows that $P=\bigcup_{n=1}^{\infty} x_{n}$ is closed, while the set $Q=f P=$ $\mathrm{U}_{n=1}^{\infty} y_{n}$ is not (since $y^{\prime} \in \bar{Q} \backslash Q$ ). This contradiction completes the proof 
of the lemma.

We now proceed to the

Proof of (1.1). Let $\left\{G_{n}\right\}$ be a countable family of open subsets of $\beta X$ such that $X=\bigcap_{n=1}^{\infty} G_{n}$. We write $\gamma_{n}$ for some covering of $X$ (by open sets in $X$ ) such that the closure in $\beta X$ of each element of $\gamma$ is contained in $G_{n}$. We take a point-finite refinement $\lambda_{n}$ of $\gamma_{n}$. For $n=1,2, \cdots$, let

$$
Y_{n}=\left\{y \in Y \mid \text { no finite } \lambda_{n}^{\prime} \cong \lambda_{n} \text { covers } f^{-1} y\right\} .
$$

It is known [5] that every $G_{\delta}$-space is a $k$-space. Thus, by Lemma (1.2), $Y_{n}$ is discrete in $Y$. We write $Y_{0}=Y \backslash \bigcup_{n=1}^{\infty} Y_{n}$.

We now prove that $f^{-1} y$ is bicompact for every $y \in Y_{0}$. For each $n$ there exists a finite $\lambda_{n}^{\prime} \subseteq \lambda_{n}$, say $\lambda_{n}^{\prime}=\left\{V_{i}^{n} \mid i=1, \cdots, k(n)\right\}$, such that $f^{-1} y \leqq \bigcup_{i=1}^{k(n)} V_{i}^{n}$. Then $F_{n}$, the closure of $\bigcup_{i=1}^{k(n)} V_{i}^{n}$ in $\beta X$, is bicompact, and $f^{-1} y \subseteq F_{n} \subseteq G_{n}$. Therefore

$$
f^{-1} y \subseteq F=\bigcap_{n=1}^{\infty} F_{n} \subseteq \bigcap_{n=1}^{\infty} G_{n}=X,
$$

where $F$ is bicompact. As $f^{-1} y$ is closed in $X$, it follows that $f^{-1} y$ is bicompact too. This completes the proof of (1.1).

REMARK. As the proof shows, a result analogous to (1.1) could be obtained for $k$-spaces $X$ which, for some cardinal $\tau$, are $G_{\delta(\tau)}$-spaces (i.e. an intersection of $\tau$ open subsets of $\beta X$ ). In particular, taking $\tau=1$, we conclude: If $f: X \rightarrow Y$ is a closed mapping, and if $X$ is point-paracompact and locally bicompact, then the set of all $y \in Y$ such that $f^{-1} y$ is not bicompact is discrete in $Y$. This is a slight generalization of a theorem of $\mathrm{K}$. Morita [11], whose proof needs the assumption that $X$ is paracompact and locally bicompact.

In case $X$ is, a Lindelöf space, the conclusion in (1.1) can be simplified.

Corollary (1.3). If $X$ is a Lindelö $G_{\delta}$-space, and if $f: X \rightarrow Y$ is a closed map, then $f^{-1} y$ is bicompact for all but countably many $y \in Y$.

Proof. Since a (regular) Lindelöf space is paracompact, and hence surely point-paracompact, Theorem (1.1) is applicable. Now $Y$, as the continuous image of the Lindelöf space $X$, is itself Lindelö, and hence all its discrete subsets are countable. Hence the set $\bigcup_{n=1}^{\infty} Y_{n}$ in (1.1) is countable, and that proves the corollary.

2. Closed mappings of spaces with countable net. The class 
of spaces with countable net (see the introduction for definition of net) contains all separable metric spaces and all their continuous images. Spaces with countable net are Lindelöf, and hence paracompact.

The main result of this section (Theorem (2.1)) is similar to Corollary (1.3), but the hypotheses are different. Note that the hypotheses of (1.3) are satisfied by complete separable metric spaces, while the hypotheses of (2.1) are satisfied by all separble metric spaces. ${ }^{11}$

Theorem (2.1). If $X$ is a space with countable net, and $f: X \rightarrow Y$ is a closed mapping, then $f^{-1} y$ is bicompact for all but countably many $y \in Y$.

The proof is based on Lemma (2.2) below, which will also be used in the proof of Theorem (2.3). We will use the following terminology: If $X$ is a space with a net $\gamma$, and if $x \in X$, then an $x$-sequence is a sequence $\left\{S_{n}(x)\right\}$, with $x \in S_{n}(x) \in \gamma$ for all $n$, such that any sequence $\left\{x_{n}\right\}$ with $x_{n} \in S_{n}(x)$ for all $n$ has an accumulation point in $X$.

Lemma (2.2). Let $f: X \rightarrow Y$ be a closed mapping of a normal space $X$ with net $\gamma$, such that for each $y \in Y$ there exists an $x \in f^{-1} y$ possessing an $x$-sequence $\left\{S_{n}(x)\right\}$. Let $Y_{1}$ be the set of all $y \in Y$ such that $f^{-1} y$ is not countably compact. Then card $Y_{1} \leqq$ card $\gamma$.

Proof. Without loss of generality, we may suppose that $S_{1} \cap S_{2} \in \gamma$. for every pair $S_{1}, S_{2} \in \gamma$. We define $Y_{0}$ as the set of all $y \in Y$ such that $y=\bigcap\left\{f(S) \mid S \in \gamma^{\prime}\right\}$ for some finite subcollection $\gamma^{\prime} \leqq \gamma$. Clearly card $Y_{0} \leqq$ card $\gamma$ (if $\gamma$ is infinite). Consider any point $y \in Y \backslash Y_{0}$. Our purpose is to show that $f^{-1} y$ is countably compact. Then the conclusion of the theorem will follow.

Let $x \in f^{-1} y$ be a point with an $x$-sequence $\left\{S_{n}(x)\right\}$. Suppose that $F=f^{-1} y$ is not countably compact, and pick $x_{1}, x_{2} \cdots$ is $F$ such that $x_{i}$ is discrete. By an obvious induction (using the normality of $X$ ), we can construct a discrete sequence $\left\{U_{i}\right\}$ of open sets such that $x_{i} \in U_{i}$. Now, again by induction, we define three sequences $\left\{x_{n}\right\},\left\{x_{n}^{\prime}\right\}$, and $\left\{0_{n} x\right\}$, where $x_{n}, x_{n}^{\prime} \in X$ and $0_{n} x$ is a neighborhood of $x$, such that

(a) for $n>k, 0_{k} x$ contains $x_{n}$;

(b) for $n \leqq k, X \backslash\left(0_{k} x\right)^{-} \supseteqq f^{-1} f x_{n}$;

(c) for all $n, x_{n} \in S_{n}(x)$;

(d) for all $n>1, x_{n}^{\prime} \in U_{n}$;

(e) for all $n, f x_{n}=f x_{n}^{\prime}$.

We take $x_{1}$ to be any point of $X \backslash F$, and for $0_{1} x$ any neighborhood of

1 For separable metric $X,(2.1)$ also follows from a recent result of N. Lashnev. 
$x$ which satisfies (b) (with $n=k=1$ ). Suppose that $x_{n}, x_{n}^{\prime}$, and $0_{n} x$ are already defined for $n \leqq k$ so as to satisfy (a)-(e). Since $\gamma$ is a net, there exist $S, S^{\prime} \in \gamma$ such that $x_{k+1} \in S \subseteq 0_{k} x$ and $x_{k+1} \in S^{\prime} \subseteq U_{k+1}$. Let $S^{*}=S \cap S_{k+1}(x)$. Then $S^{*} \in \gamma$ and $\left(f S^{*} \cap f S^{\prime}\right) \backslash y \neq \varnothing$.

Let $x_{k+1} \in S^{*}, \quad x_{k+1}^{\prime} \in S^{\prime}$ be points such that $f x_{k+1}=f x_{k+1}^{\prime} \neq y$. Finally, we take for $0_{k+1} x$ some neighborhood of $x$ such that

$$
x \in 0_{k+1} x \leqq\left(0_{k+1} x\right)^{-} \subseteq X \backslash \bigcup_{i=1}^{k+1} f^{-1} f x_{i} .
$$

Clearly conditions (a)-(e) are satisfied, and we can go further in our induction.

Since $\left\{S_{n}(x)\right\}$ is an $x$-sequence, the set $P=\left\{x_{n}\right\}$ has in $X$ an accumulation point, say $x^{*}$. The conditions imply that $x^{*} \notin f^{-1} f P$. Then $f x^{*} \in(f P)^{-} \backslash f P$, and hence $f P$ is not closed. On the other hand, $f P=f Q$, where $Q=\left\{x_{n}^{\prime}\right\}$. Since $x_{n}^{\prime} \in U_{n}$, and the family $U_{n}$ is discrete, $Q$ is closed in $X$. Thus $f Q$ is closed in $Y$, and we have a contradiction which completes the proof of (2.2).

Proof of (2.1). In a space $X$ with a countable net $\gamma$, every $x \in X$ has an $x$-sequence, namely all elements of $\gamma$ containing $x$. Also, as observed earlier, such an $X$ is paracompact, and hence it is normal and all closed, countably compact subsets are bicompact. We therefore see that (2.1) follows from (2.2).

In the following theorem, a space $X$ is of point-countable type (see [5]) if it is the union of bicompact subsets $K$ having a countable base of neighborhoods $\left\{U_{n}\right\}$ (i.e., if $V \supseteqq K$ is open, then $K \cong U_{n} \subseteq V$ for some $n) .^{2)}$ All first-countable spaces, and all $p$-spaces (in the sense of [5]) are spaces of point-countable type.

THEOREM (2.3). Let $X$ be a normal point-paracompact space of point-countable type, with a net $\gamma$ of cardinality $\leqq \tau$. If $f: X \rightarrow Y$ is a closed mapping, and

$$
Y_{1}=\left\{y \in Y \mid f^{-1} y \text { is not bicompact }\right\},
$$

then card $Y_{1} \leqq \tau$.

Proof. Let us show that every $x \in X$ has a $\gamma$-sequence $\left\{S_{n}(x)\right\}$, so that (2.2) applies. Pick a compact $K \subseteq X$ such that $x \in K$ and $K$ has a countable base of neighborhoods $\left\{U_{n}\right\}$. Clearly, if we pick $S_{n}(x)$ so that $x \in S_{n}(x) \subseteq U_{n}$, then $\left\{S_{n}(x)\right\}$ is an $x$-sequence. Applying (2.2), we have the conclusion of the theorem since, in a point-paracompact space, closed countably compact subsets are bicompact.

${ }^{2}$ For point-paracompact spaces, the spaces of point-countable type are the same as the q-spaces in the sense of E. Michael [10]. 


\section{An application.}

THEOREM (3.1). If $X$ is a countable-dimensional space with countable net $\gamma$, and $f: X \rightarrow Y$ is a closed mapping onto an uncountable-dimensional space $Y$, then

$$
Y_{1}=\left\{y \in Y \mid \operatorname{card}\left(f^{-1} y\right) \geqq \mathfrak{c}\right\}
$$

is uncountable dimensional.

The proof is based on two lemmas.

Lemma (3.2). Let $f: X \rightarrow Y$ be a closed mapping of a space $X$ with a countable net $\gamma=\left\{S_{i}\right\}$ such that, for each $y \in Y$, the set $f^{-1} y$ contains a point which is isolated in $f^{-1} y$. Then $Y$ is a countable sum of subspaces, each of which is homeomorphic to a subspace of $X$.

Proof. Without loss of generality, we may suppose that all $S_{i} \in$ $\gamma$ are closed in $X$. For each $i$, let $f_{i}^{*}=f \mid S_{i}$, and let

$$
X_{i}=\left\{x \in S_{i} \mid f_{i}^{*-1} f_{i}^{*} x=x\right\} .
$$

Let $Y_{i}=f X_{i}$, and let us show that $X_{i}$ is homeomorphic to $Y_{i}$ and $Y=\bigcup_{i=1}^{\infty} Y_{i}$

Since $f$ is closed, so is its restriction $f_{i}^{*}$ to the closed set $S_{i}$. Now $X_{i}=f_{i}^{*-1} Y_{i}$, so if $f_{i}: X_{i} \rightarrow Y_{i}$ is defined by $f_{i}=f_{i}^{*} \mid X_{i}$, then $f_{i}$ is also closed. Since $f_{i}$ is clearly continuous and one-to-one, it is a homeomorphism.

It remains to show that $Y=\bigcup_{i=1}^{\infty} Y_{i}$. Let $y \in Y$, and let $x$ be an isolated point of $f^{-1} y$. Then $0 x=X \backslash\left(f^{-1} y \backslash x\right)$ is a neighborhood of $x$. Since $\gamma$ is a net in $X$, there exists an $S_{k} \in \gamma$ such that $x \in S_{k} \subseteq 0 x$. Then $x=S_{k} \cap f^{-1} y$, and thus $x \in X_{k}$. It follows that

$$
y=f x \in f_{k} X_{k}=Y_{k} \subseteq \mathbf{U}_{i=1}^{\infty} Y_{i} \text {. }
$$

This completes the proof of (3.2).

Lemma (3.3). If $f: X \rightarrow Y$ is a closed mapping of a space $X$ with a countable net $\gamma$, such that card $\left(f^{-1} y\right)<\mathrm{c}$ for all $y \in Y$, then $Y$ is a countable sum of subspaces each of which is homeomorphic. to a subspace of $X$.

Proof. By (2.1), $Y=Y_{0} \cup Y_{1}$, where $Y_{0}$ is countable and $f^{-1} y$ is bicompact for each $y \in Y_{1}$. Consider $f_{1}=f \mid X_{1}$, where $X_{1}=f^{-1} Y_{1}$. If $y \in Y_{1}$, then card $f_{1}^{-1} y<\mathfrak{c}$, so $f_{1}^{-1} y$ has an isolated point. Thus $X_{1}$, 
$f_{1}$ satisfy the condition of (3.2), and hence $Y_{1}$ is a countable sum of subspaces which are homeomorphic to subspaces of $X_{1} \subseteq X$. But $Y_{0}$ is a countable sum of points, and hence the conclusion follows.

Proof of (3.1). Let $Y_{0}=\left\{y \in Y \mid\right.$ card $\left.f^{-1} y<c\right\}$. Consider $f_{0}=$ $f \mid X_{0}$, where $X_{0}=f^{-1} Y_{0}$. The map $f_{0}: X_{0} \rightarrow Y_{0}$ satisfies all the conditions of (3.3). Since $X$ is a space with a countable net, $X$ is hereditarily Lindelöf. Hence every subspace of $X$ is countabledimensional [17]. By (3.3), $Y_{0}$ is thus also countable-dimensional. Therefore $Y \backslash Y_{0}$ is uncountable-dimensional, and the proof of (3.1) is complete.

Theorem (3.1) is new even for compact metric $X$, where it can be rephrased as follows:

CoRollary (3.4). If $f: X \rightarrow Y$ is a mapping of a countabledimensional compact metric space $X$ onto an uncountable-dimensional space $Y$, then $\left\{y \in Y \mid\right.$ card $\left.f^{-1} y=\mathfrak{c}\right\}$ is uncountable-dimensional.

REMARK 1. Another application of (2.2): A space is called dyadic [14] if there exists a dyadic bicompact extension of this space. We call a dyadic space nowhere countable if there are no nonempty countable open sets in it.

THEOREM (3.5). If a nowhere countable dyadic space $Y$ is a closed image of a separable metric space, then there exists a countable base in $Y$.

Proof. By (3.1), there exists a countable set $Y_{0} \subseteq Y$ such that, if $Y_{1}=Y \backslash Y_{0}, X_{1}=f^{-1} Y_{1}$, and $f_{1}: X_{1} \rightarrow Y_{1}$ is defined by $f_{1}=f \mid X_{1}$, then $f_{1}$ is a perfect map. Hence $Y_{1}$ is a space with countable base. Since $Y$ is nowhere countable, $Y_{1}$ is dense in $Y$. Hence $Y$ is metrizable, by a theorem of B. Efimov [7]. This completes the proof. ${ }^{3)}$

REMARK 2. The following generalization of a theorem of J. Nagata [13] could also be proved.

THEOREM (3.6). Let $X$ be a compact metric space, and $f: X \rightarrow Y$ a map such that $f^{-1} y$ is finite for all $y \in Y$. Then, for each countable-dimensional $X^{\prime} \cong X$, the space $Y^{\prime}=f X^{\prime}$ is countabledimensional.

${ }^{3}$ This theorem shows a simple way for constructing nondyadic spaces. 


\section{BIBLIOGRAPHY}

1. P. S. Aleksandrov, Some results in the theory of topological spaces obtained within the last twenty-five years, Uspehi Mat. Nauk (92) 15 (1960), 25-95. (Russian Math. Surveys 15 (1960), 23-83).

2. - On some basic irends in general topology. Uspehi Mat. Nauk 19 (1964), $3-46$.

3. A. Arhangel'skil, An addition theorem for the weight of sets lying in bicompacts, Dokl. Akad. Nauk SSSR 126 (1959), 239-241.

4. - Some type of factor mappings and the relations between classes of topological space, Dokl. Akad. Nauk SSSR 153 (1963), 743-746. (Soviet Math. Dokl. 4 (1963), 1726-1729).

5. - On a class of spaces containing all metric and all bicompact spaces, Dokl. Akad. Nauk SSSR 151 (1963), 751-754, (Soviet Math. Dokl. 4 (1963), 1051-1055).

6. A. Archangielski and W. Holsztynski, Sur les reseaux dans les espaces topologiques, Bull. Acad. Polon. Sci. Ser. Math. 11 (1963), 493-797.

7. B. Efimov, On dyadic spaces, Dokl. Akad. Nauk SSSR 151 (1963), 1021-1024. (Soviet Math. Dokl. 4 (1963), 1131-1134).

8. J. L. Kelly, General Topology, van Nostrand, New York, 1955.

9. B. T. Levšenko, On the concept of compactness and point-finite coverings, Mat. Sb. N. S. 42 (84) (1957), 478-484.

10. E. Michael, A note on closed maps and compact sets, Israel J. Math. 2 (1964), 173-176.

11. K. Morita, On closed mappings, Proc. Japan Acad. 32 (1956), 539-543.

12. K. Morita and S. Hanai, Closed mappings and metric spaces, Proc. Japan Acad.

32 (1956), 10-14.

13. J. Nagata, On countable dimensional spaces, Proc. Japan Acad. 34 (1958), 146-149.

14. V. I. Ponomarev, On dyadic spaces, Fund. Math. 52 (1963), 1013-1016.

15. E. G. Skljarenko, Some remarks on spaces having an infinite number of dimensions. Dokl. Akad. Nauk SSSR 126 (1959), 1203-1206.

16. - Two theorems on infinite-dimensional spaces, Dokl. Akad. Nauk SSSR 143 (1962), 1053-1056. (Soviet Math. Dokl. 3 (1962), 547-550).

17. Yu. M. Smirnov, On the theory of finally compact spaces, Ukrain. Mat. Zurnal 3 (1951), 52-60.

18. A. H. Stone, Metrizability of decomposition spaces, Proc. Amer, Math. Soc. 7 (1956), 690-700.

19. E. A. Vaǐnšteǐn, On closed mappings, Moskov. Gos. Univ. Uč. Zap. 155, Mat. 5 (1952), 3-53.

Received May 14, 1965.

UNIVERSITY OF MOSCOW

Moscow, U.S.S.R. 


\section{PACIFIC JOURNAL OF MATHEMATICS}

\section{EDITORS}

H. SAMELSON

Stanford University

Stanford, California

R. M. BLUMENTHAL

University of Washington

Seattle, Washington 98105

\section{*J. DugundJI}

University of Southern California Los Angeles, California 90007

RICHARD ARENS

University of California

Los Angeles, California 90024

\section{ASSOCIATE EDITORS}

E. F. BECKENBACH
F. WOLF

K. YosIDA

\section{SUPPORTING INSTITUTIONS}

\author{
UNIVERSITY OF BRITISH COLUMBIA \\ CALIFORNIA INSTITUTE OF TECHNOLOGY \\ UNIVERSITY OF CALIFORNIA \\ MONTANA STATE UNIVERSITY \\ UNIVERSITY OF NEVADA \\ NEW MEXICO STATE UNIVERSITY \\ OREGON STATE UNIVERSITY \\ UNIVERSITY OF OREGON \\ OSAKA UNIVERSITY \\ UNIVERSITY OF SOUTHERN CALIFORNIA
}

\author{
STANFORD UNIVERSITY \\ UNIVERSITY OF TOKYO \\ UNIVERSITY OF UTAH \\ WASHINGTON STATE UNIVERSITY \\ UNIVERSITY OF WASHINGTON \\ AMERICAN MATHEMATICAL SOCIETY \\ CHEVRON RESEARCH CORPORATION \\ TRW SYSTEMS \\ NAVAL ORDNANCE TEST STATION
}

Mathematical papers intended for publication in the Pacific Journal of Mathematics should be typewritten (double spaced). The first paragraph or two must be capable of being used separately as a synopsis of the entire paper. It should not contain references to the bibliography. Manuscripts may be sent to any one of the four editors. All other communications to the editors should be addressed to the managing editor, Richard Arens at the University of California, Los Angeles, California 90024 .

50 reprints per author of each article are furnished free of charge; additional copies may be obtained at cost in multiples of 50 .

The Pacific Journal of Mathematics is published monthly. Effective with Volume 16 the price per volume (3 numbers) is $\$ 8.00$; single issues, $\$ 3.00$. Special price for current issues to individual faculty members of supporting institutions and to individual members of the American Mathematical Society: $\$ 4.00$ per volume; single issues $\$ 1.50$. Back numbers are available.

Subscriptions, orders for back numbers, and changes of address should be sent to Pacific Journal of Mathematics, 103 Highland Boulevard, Berkeley 8, California.

Printed at Kokusai Bunken Insatsusha (International Academic Printing Co., Ltd.), No. 6, 2-chome, Fujimi-cho, Chiyoda-ku, Tokyo, Japan.

PUBLISHED BY PACIFIC JOURNAL OF MATHEMATICS, A NON-PROFIT CORPORATION

The Supporting Institutions listed above contribute to the cost of publication of this Journal, but they are not owners or publishers and have no responsibility for its content or policies.

* Paul A. White, Acting Editor until J. Dugundji returns. 


\section{Pacific Journal of Mathematics}

\section{Vol. 18, No. 2 \\ April, 1966}

Alexander V. Arhangelskii, On closed mappings, bicompact spaces, and a problem of P. Aleksandrov .............................. 201

A. K. Austin, A note on loops . . . . . . . . . . . . . . . . . . . . . . . . . . . . 209

Lawrence Peter Belluce and William A. Kirk, Fixed-point theorems for families of contraction mappings...................... 213

Luther Elic Claborn, Every abelian group is a class group ............ 219

Luther Elic Claborn, A note on the class group .................. 223

Robert Stephen De Zur, Point-determining homomorphisms on multiplicative semi-groups of continuous functions............. 227

Raymond William Freese, A convexity property ................ 237

Frederick Paul Greenleaf, Characterization of group algebras in terms of their translation operators ......................... 243

Andrzej Hulanicki, On the spectral radius of hermitian elements in group algebras....................................... 277

Michael Bahir Maschler and Bezalel Peleg, A characterization, existence proof and dimension bounds for the kernel of a game ............ 289

Yiannis (John) Nicolas Moschovakis, Many-one degrees of the predicates

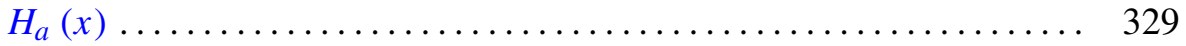

G. O. Okikiolu, $n$th order integral operators associated with Hilbert transforms.

C. E. Rickart, Analytic phenomena in general function algebras ... 361

K. N. Srivastava, On an entire function of an entire function defined by Dirichlet series

Paul Elvis Waltman, Oscillation criteria for third order nonlinear differential equations .......................... 